Bioscientia Medicina: Journal of Biomedicine \& Translational Research

Journal Homepage: www.bioscmed.com

\title{
Incidence of Hard Tissue Disease on Periapical Radiographic Examination at Prima Oral Dental Hospital Medan Indonesia
}

\section{Andre Yonathan Purba1, Mellisa Sim², Phimatra Jaya Putra ${ }^{3 *}$}

${ }^{1}$ Department of Dentistry, Faculty of Dentistry, Universitas Prima Indonesia, Medan, Indonesia

${ }^{2}$ Department of Dental Sciences, Faculty of Dentistry, Universitas Prima Indonesia, Medan, Indonesia

${ }^{3}$ Department of Oral Maxillofacial Radiology, Faculty of Dentistry, Universitas Prima Indonesia, Medan, Indonesia

\section{A R T I C L E I N F O \\ Keywords: \\ Caries \\ Periapical radiography \\ Dental hard tissue \\ Superficial caries \\ *Corresponding author: \\ Phimatra Jaya Putra \\ E-mail address: \\ phimatrajayaputra@unprimdn.ac.id}

All authors have reviewed and approved the final version of the manuscript.

\begin{abstract}
A B S T R A C T
Background. Caries is a chronic infection of dental hard tissue. The development of caries is not limited to the tooth area, but caries can progress to the pulp chamber resulting in periapical lesions and abnormalities if not treated. Early detection of oral disease through radiographic examination is important, one of which is through periapical radiography. Methods: This type of research is descriptive. The sample of this research is periapical radiography of cases of hard tissue disease at Prima Oral Dental Hospital period April - May 2021 as many as 78 photos. Sampling in this study was done by random sampling. Data were analyzed descriptively. Results: Based on the interpretation of 78 photos periapical radiographs, it was found that the highest number of caries cases at Prima Oral Dental Hospital was superficial caries as much as $48.7 \%$, followed by media caries as much as $43.6 \%$ and profunda caries only $7.7 \%$. The mean and standard deviation of superficial caries depth was $3.51 \pm 1.348$; medium caries $6.88 \pm 1.122$ and profunda caries $10.00 \pm 1.549$. Conclusion: Superficial caries is the most caries case found on periapical radiographic examination at Prima Oral Dental Hospital, while profunda caries is the least caries case.
\end{abstract}

https://doi.org/10.37275/bsm.v6i4.481

\section{Introduction}

Dental and oral health is part of body health that cannot be separated from one another because it will affect the health of the body as a whole. Most people are not aware of the emergence of dental and oral diseases originating from oral health. This is influenced by the behavior of people who are less concerned about dental and oral hygiene which has become a habit. ${ }^{1}$ Incidence Oral cavity disease is a type of disease that is in the first order of the list of the top ten diseases that most Indonesian people complain about. ${ }^{2}$ This can happen because the majority of Indonesian people are still lacking in maintaining dental and oral health.
Diseases of the oral cavity can cause damage to soft tissues such as oral mucosal lesions or damage to hard tissues of the oral cavity such as caries. ${ }^{3}$ Dental caries is a chronic infectious disease caused by a progressive demineralization process in the hard tissues of the crown and root surfaces of the teeth, and has a long development period. Another opinion states that caries is a hard tissue disorder of the teeth characterized by the destruction of enamel and dentin caused by the metabolism of bacteria in plaque. ${ }^{4}$

Incidence of caries shows that the prevalence of dental caries in Indonesia has increased to $88.8 \%$ and 
this condition tends to be high in all age groups. This causes dental caries to become a priority for dental and oral health problems. Dental caries is also one of the problems in the field of dental and oral health that many Indonesian people suffer from. The development of caries is not limited to the dental area, but caries can progress to the pulp chamber resulting in periapical lesions and abnormalities if not treated. This is because people will check the problem to the dentist if they have problems with mastication, swallowing, and speaking disorders. Society considers that caries is considered a mild disease, non-communicable, and not lifethreatening. ${ }^{5}$

Based on the percentage of EMD data (Effective Medical Demand) only $8.1 \%$, it indicates that most Indonesian people leave the dental and oral diseases they suffer, especially caries, without treatment. This also shows that some people do not yet have awareness of the importance of maintaining dental and oral health, thus allowing many people to suffer from infections in the periapical area as a result of the spread of bacteria from caries and necrotic pulp. To diagnose various diseases of the oral cavity, dentists need to perform radiographic examinations, both intraoral and extraoral radiographs. Early detection of oral disease through radiographic examination is important because it can help dentists to make a diagnosis. Dental radiography is an examination tool to see oral manifestations in the oral cavity which cannot be seen from clinical examination but can clearly see features such as the expansion of periodontal disease, dental caries and other pathological abnormalities in the oral cavity. Dental radiographs serve as a guide to maximize the results of the diagnosis seen from image interpretation. ${ }^{6-8}$

This study is a descriptive study that describes the incidence and features of hard tissue disease in periapical radiographs at the Prima Dental Oral Hospital (RSGM) Medan Indonesia. This study presents data that is expected to be a reference and initial data to become reference data for preventive, curative and rehabilitative activities. for preventive, curative, and rehabilitative activities.

\section{Methods}

The research design in this study is a descriptive observational method, which aims to describe or describe the number of cases of hard tissue disease on periapical radiographic examination at RSGM Prima, Medan, Indonesia. the study was conducted from April - to June 2021. The sample used in. this study consisted of 78 periapical radiographs of caries cases (superficial, media, profunda) Sampling in this study was done by random sampling. This study assessed the radiological features of superficial, middle, and profunda caries as well as the depth of dental caries.

Data analysis was performed with the help of SPSS version 25 software. Univariate analysis was performed to describe the distribution of the frequency and incidence of superficial, middle, and profunda caries as well as the depth of dental caries.

\section{Results}

Table 1. Distribution of caries frequency on periapical radiography

\begin{tabular}{|c|c|c|c|c|c|c|}
\hline \multirow{2}{*}{ Type of caries } & \multirow{2}{*}{ Total } & \multirow{2}{*}{$\%$} & \multicolumn{4}{|c|}{ Type of tooth } \\
\cline { 4 - 7 } & & & Anterior & $\%$ & Posterior & $\%$ \\
\hline Superficial & 38 & 48.7 & 4 & 10.5 & 34 & 89.5 \\
\hline Media & 34 & 43.6 & 5 & 14.7 & 29 & 85.3 \\
\hline Profunda & 6 & 7,7 & 3 & 50.0 & 3 & 50.0 \\
\hline Total & 78 & 100.0 & 12 & 15.4 & 66 & 84.6 \\
\hline
\end{tabular}

Table 1 shows that most cases of caries were superficial caries amounting to 38 cases (48.7\%), while profunda caries were a case of the least caries on periapical radiographic examination at Prima Oral Dental Hospital. From table 1 above, it can also be seen that the posterior teeth experienced more of the three types of caries, namely $84.6 \%$ compared to only $15.4 \%$ for anterior teeth.

The types of teeth that experienced caries hard tissue abnormalities in this study appeared to be 
greater in the posterior teeth, which was $84.6 \%$ compared to the anterior at $15.4 \%$. experienced caries proportional between anterior and posterior.

Table 2. Distribution of caries depth on periapical radiographic examination at Prima Oral Dental Hospital

\begin{tabular}{|c|c|c|}
\hline Type of caries & Mean & Standard deviation \\
\hline Superficial & 3.51 & 1.348 \\
\hline Media & 6.88 & 1.549 \\
\hline Profunda & 10.00 & 1.122 \\
\hline
\end{tabular}

Table 2 shows that the mean and standard deviation of superficial caries depth is $3.51 \pm 1,348$; medium caries $6.88 \pm 1.122$ and profunda caries $10.00 \pm 1.549$.
From these results, it can be seen that profunda caries have the greatest caries depth compared to superficial and media caries.

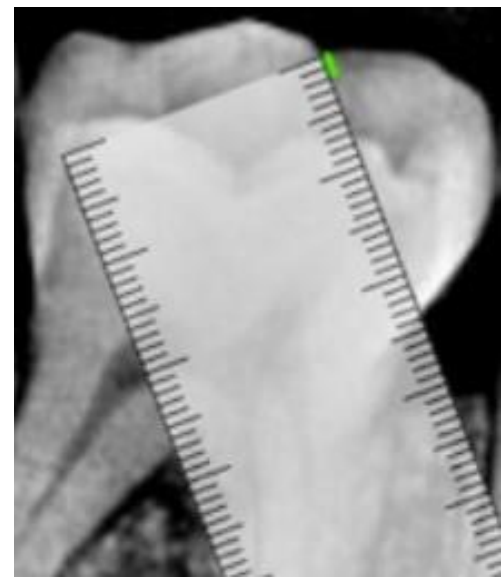

(A)

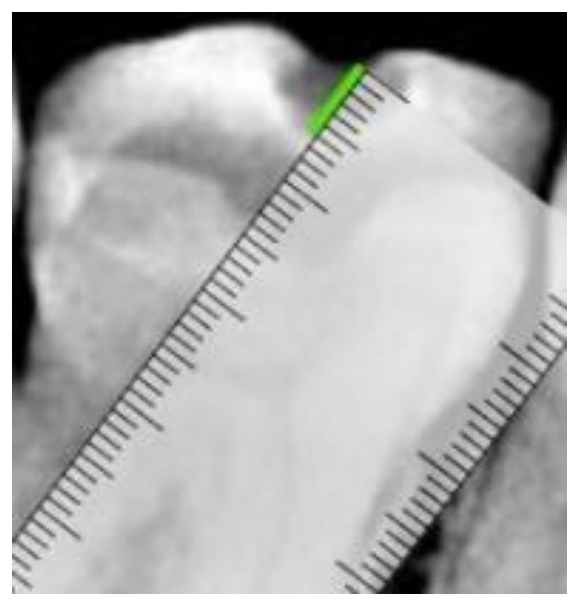

(B)

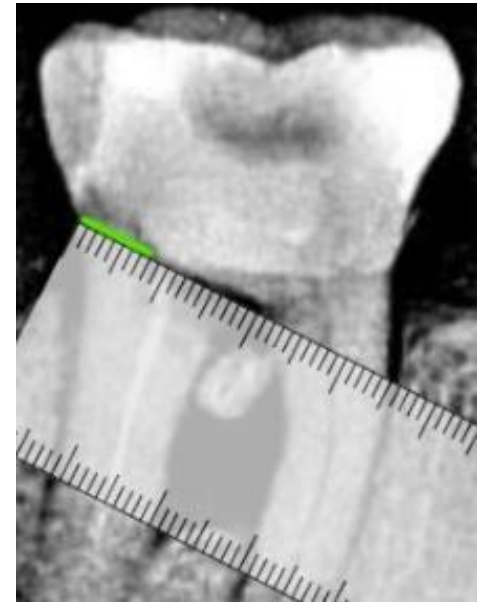

(C)

Figure 1:

A. In Figure A, Superficial Caries on tooth 36 is $2 \mathrm{~mm}$ profunda as measured using a virtual ruler (Snip $\&$ sketch).

B. In Figure B, you can see media caries on tooth 46 as profunda as $6 \mathrm{~mm}$ as measured using a virtual ruler (Snip \& sketch).

C. Figure C shows profunda caries on tooth 37 as profunda as $8 \mathrm{~mm}$ as measured using a virtual ruler (Snip $\&$ sketch).

\section{Discussion}

The study of the incidence of hard tissue disease on periapical radiographic examination aims to determine the number of diseases of hard tissue on periapical radiographic examination at Prima Oral Dental Hospital. The number of radiographs of caries cases (superficial, media, profunda) that were interpreted was 78 photos. A study states that radiographic examination plays an important role in every stage of dental case management. Periapical radiography is one of the most commonly used intraoral radiographic techniques in endodontic treatment. ${ }^{9}$ In this study, the Periapical radiographs were used to determine the number of hard tissue diseases of the teeth, in this case, caries. From the results of the examination carried out on 78 periapical radiographs, it was found that the highest number of caries cases at Prima Oral Dental Hospital. was superficial caries as much as $48.7 \%$, followed by media caries as much as $43.6 \%$ and profunda caries only $7.7 \%$. The results of this study are following a study which stated that the most common 
oral hard tissue disease found through periapical radiographic data was caries and based on the results of the radiographic examination of the first molars in children aged 6-9 years with 10-12 years, it was found that the majority of caries was superficial. (62.8\%), media caries $(6.4 \%)$ and profunda caries $(3.6 \%) .{ }^{10}$ This is supported by the results of this study that the mean and standard deviation of caries depth from superficial caries is $3.51 \pm 1.348$; medium caries $6.88 \pm 1.122$ and profunda caries $10.00 \pm 1.549$. Another study also showed the same results as this study that profunda caries had a deeper caries depth of $59.76 \mathrm{~mm}$ compared to $15.95 \mathrm{~mm}$ superficial caries and $24.29 \mathrm{~mm}$ medium caries. Furthermore, the results of this study stated that from the interpretation of periapical radiographs in this study, it was found that profunda caries were deeper caries than media and superficial caries. ${ }^{11}$ In this study, the teeth with the most caries were the posterior teeth. This is in line with studies that state that the posterior teeth have the most caries. ${ }^{12}$ Another study stated that the permanent first molar is a tooth that is very susceptible to caries. Caries in the first permanent molars are the main cause of the high prevalence of dental extractions. This is because the teeth are the first permanent teeth to erupt, besides that, the anatomical shape that has a deep fit and fissure can facilitate the accumulation of food debris and microorganisms that are difficult to clean by brushing your teeth, making it easy for caries to occur. 13

Caries are a disease of the hard tissues of the teeth, namely enamel, dentin, and cementum caused by several factors that involve complex risk and protective factors. One of the causes of caries is microorganisms. These microorganisms will trigger an inflammatory response in the pulp. The main microorganisms that cause caries are Streptococcus mutans, Streptococcus mutans can produce acid very quickly, the speed of acid formation by Streptococcus mutans bacteria is closely related to the occurrence of dental caries. ${ }^{14}$

Superficial caries is caries that has just reached or has reached the outermost part of the tooth (enamel) and has not yet affected the dentin, while middle caries is caries that has reached or reached the dentin but has not yet affected half of the dentin and profunda caries is caries that has reached or reached half of the dentin even up to the pulp. In Listrianah's opinion, it can be seen that profunda caries have the deepest depth of caries severity compared to the other two caries. The deeper caries, the more severe the disease. Not a few teeth can not be saved due to caries that are too severe until the entire clinical crown is lost due to the caries process and leaving only the root. This causes the tooth to be extracted, and the masticatory function will be reduced. 15

\section{Conclusion}

Superficial caries was the most common caries case found on periapical radiographic examination at Prima Oral Dental Hospital, while profunda caries was the least caries case.

\section{References}

1. Farges, JC, Licht, BA, Renard, E., Ducret, M., Gaudin, A., Smith, AJ, et al. Dental pulp defense and repair/mechanisms in dental caries. Journal of Inflammation Mediators. 2015; 1-16.

2. Giudice, RL., Nicita, F., Puleio, F., Alibrandi, A., Cervino, G., Lizio, USA., et al. Accuracy of periapical radiography and CBCT in endodontic evaluation. International Journal of Dentistry. 2018; (2514243): 1-7.

3. Handayani H., and Arifah AN. The Relation of oral and dental health knowledge, attitude and behavior to the dental health status of student at SMP/Mts Pondok Pesantren Putri Ummul Mukminin. Makassar Dent. 2016; 5(2): 44-50.

4. Kaval ME., Tekin, U., and Unal, T. Radiographic and histological evaluation of persistent periapical lesions associated with endodontic failures after apical microsurgery. 
Int Endod J. 2016; 49: 1011-9.

5. Kusuma, AP., and Taiyep, AM. Description of dental caries in second class students of public elementary school 20 Sungaiselan. Health Media Makassar Health Polytechnic. 2020; 15(2):238-244.

6. Listrianah, Zainur, RA Hisata, Levi Saputri. overview of caries in the first permanent molars in state elementary School 13 Palembang in 2018. JPP (Jurnal of Health Poltekkes Palembang). 2018; 13(2): 136-149

7. Manoy, NT, Kawengian, Shirley ESMintjelungan, Christy N. Overview of caries permanent first molars and nutritional status at catholic elementary school 06 Manado.EGigi. 2015; 3(3).

8. Neville, B., Damm, DD., Allen, C., and Chi A. Pulpal and periapical diseases. oral and maxillofacial pathology. 4rd edition. Canada: Elsevier. 2015.

9. Oliveira, DBP., Camara, C., and Aguiar, CM Prevalence of Endodontic diseases: an epidemiological evaluation in a brazilian subpopulation. brazilian. journal of oral sciences. 2016; 15(2): 119-123.

10.Prisinda, D., Wahyuni, IS., Andsetyanto, P., and Zenab, Y. Characteristics of caries in the mixed dentition period in children aged 6-7 years in Tanjungsari district, sumedang. Padjadjaran J Dent Res Student. 2017; 1(2): 95-101.

11.Utami, ID., Pramanik, F., and Epsilawati, L. Proportion of radiographic features of periapical lesions of necrotic teeth on periapical radiographs. Padjadjaran J Dent Res Student. 2019; 3(1): 64-69.

12.Wei, LX., How, F., Min, P., Zafri, S., Syed, B., Khaw, E., et al. Radiographic assessment of apical root resorption in inflammatory periapical pathologies. J Indian Acad Oral Med
Radiol. 2018; 30(2):132-6.

13. Whaites, E., and Drag N. Essentials of dental radiography and radiology. 5th ed. St. Louis, Missouri: Elsevier. 2013.

14.Young DA., Novy BB., Zeller GG., Hart,TC., and Truelove EL. The American dental association caries classification system for clinical practice a report of the American Dental Association Council on Scientific Affairs. JADA. 2015; 146(2), 79-86.

15.Yunus B., Nuraini.; and Wulansari DP. Hard and soft tissue lesion in oral cavity assessed by periapical and panoramic radiography. Med Clin Pract. 2020; 3(100096): 1-3. 